\title{
Inhibitors of Fruiting-body Formation and Challenge Time Experiments in Myxococcus xanthus
}

\author{
By COLIN H. CLARKE* AND IRENE NAPIER \\ School of Biological Sciences, University of East Anglia, Norwich, Norfolk NR4 7TJ, U.K.
}

(Received 12 March 1982; revised 23 June 1982)

\begin{abstract}
Purines, amino acids and their analogues, polypeptide and other antibiotics, and a range of other chemicals were screened by a spot-testing technique for inhibition of vegetative growth, or of fruiting-body formation, in the bacterium Myxococcus xanthus. Selected fruiting inhibitors were tested by challenge time-transfer experiments. In general, delayed addition of inhibitors up to the time of late aggregation prevented subsequent completion of fruiting. Conversely, cells held in the presence of a fruiting inhibitor for extended periods did not rapidly lose the ability to fruit subsequently on removal of the inhibitor.
\end{abstract}

\section{INTRODUCTION}

Under starvation conditions on a solid surface, and at a sufficiently high cell density, $M$. xanthus aggregates to foci, followed by the construction of fruiting bodies. In $M$. xanthus the fruiting body is a simple tumulus-like mound of dried slime within which a proportion of the aggregated rod-shaped vegetative cells become converted into spherical, thick-walled, dormant myxospores.

Some amino acids and their analogues, such as phenylalanine and tryptophan (Leadbetter, 1963; Dworkin, 1963), methionine (Hemphill \& Zahler, 1968), lysine (Rosenberg et al., 1973), ethionine, isoleucine or norleucine (Campos \& Zusman, 1975), and glycine (Manoil \& Kaiser, $1980 \mathrm{c}$ ) have been shown to inhibit fruiting under a range of otherwise favourable conditions. Guanosine tetraphosphate and pentaphosphate and cyclic GMP accumulation have been implicated in $M$. xanthus fruiting formation (Manoil \& Kaiser, 1980a, $b$; Ho \& McCurdy, 1980) but it has been shown that purine effects on fruiting are probably non-specific and indirect, via nutritional imbalance (Manoil \& Kaiser, 1980c).

We have tested a range of compounds for specific inhibition of fruiting in $M$. xanthus, rather than mere inhibition of growth. Selected inhibitors of fruiting have been tested by challengetransfer experiments to determine if they act at specific steps in the morphogenetic pathway leading to fruiting-body formation (Inouye et al., 1979, Morrison \& Zusman, 1979). Such experiments were performed, firstly, by placing cells of $M$. xanthus under conditions to initiate fruiting-body formation and then transferring them to the inhibitor after various times. Such experiments tested if there is a point-of-no-return beyond which the inhibitor fails to block fruiting. In the other type of experiments cells were initially incubated plus the inhibitor under otherwise fruiting conditions. After various periods they were removed from the inhibitor. Such experiments tested if the inhibited cells retained or lost their capacity to fruit during a period where this was inhibited. Thus the cells might 'mark time' at the blocked stage in the fruiting process until the inhibitor was removed. Alternatively, if blocked they might undergo changes, such as autolysis or free-lying myxospore-formation, rendering them unable to construct normal fruiting bodies subsequently when the inhibitor was later removed. 


\section{METHODS}

Strains. Myxococcus xanthus strain MD1 (formerly known as FB) was kindly provided by Professor M. Dworkin, Department of Microbiology, University of Minnesota Medical School, Minneapolis, U.S.A. It shows dispersed growth in liquid culture and yellow-tan colonial colour instability (Wireman \& Dworkin, 1975). $M$. xanthus NCIB 9412 was also used in some experiments. MD1 and NCIB 9412 differ in colonial morphology and motility but both originated from the same strain. Strains were stored as fruiting bodies on plugs of agar medium in refrigerated bijou bottles or, as working stocks, on plates of 1 CMPA medium (see below) held in the dark at room temperature.

Media. Routine medium for the growth of $M$. xanthus was $1 \%(\mathrm{w} / \mathrm{v})$ Difco Bacto Casitone (or Oxoid Tryptone)

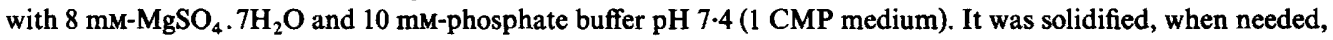
with $2 \%(w / v)$ Difco Bacto agar or Davis N.Z. agar (1 CMPA medium). Incubation was routinely at $30^{\circ} \mathrm{C}$, in a G24 New Brunswick orbital incubator under subdued light for $48 \mathrm{~h}$ in the case of liquid cultures. For fruiting body experiments, $30 \mu \mathrm{l}$ droplets of $1 \mathrm{CMP}$ cultures were spotted on to the surface of water/magnesium/phosphate/agar plates containing only $0.05 \%$ (w/v) Casitone or Tryptone (0.05 CMPA). On this semi-starvation medium cells of $M$. xanthus first undergo limited but visible multiplication, followed by aggregation and fruiting body formation. Incubation was at $30^{\circ} \mathrm{C}$ in the dark. Fruiting bodies were formed after about $3 \mathrm{~d}$.

Antibiotics. Samples of the following antibiotics were generously donated by the manufacturers: bacitracin (Apothekernes Laboratorium, Norway); valinomycin (Boehringer); capreomycin (Eli Lilly); CP-41,043 and CP41,012 (Pfizer Central Research); colomycin (Pharmax); Br-X537A and monamycin (Roche Products); colistine and bacitracine (Roussel UCLAF); bacitracin, neomycin and polymyxin B (Wellcome Foundation); hadacidin (Merck, Sharp \& Dohme); novobiocin and lincomycin (Boots).

Fruiting bodies. These were examined by both obliquely transmitted and reflected light when on agar surfaces, and by obliquely reflected light on the surface of membrane filters using low-power microscopy (PZO Mst 131 instrument). Fruiting plates were routinely examined after 3,5 and $7 \mathrm{~d}$. By reflected light mature fruiting bodies appear opaque, glistening and pearly off-white. By transmitted light mature fruits are dark and opaque with defined outlines; they are distinct from transparent aggregates which do not contain myxospores.

Transfer experiments. Areas inoculated with $30 \mu \mathrm{l}$ droplets on the surface of 0.05 CMPA plates were cut out with a sterile scapula and the agar discs transferred to the surface of other plates. Alternatively, in some experiments, fruiting bodies or cells on the surface of Gelman Metricel green or black $0.45 \mu \mathrm{m}$ porosity filters, or Uni-Pore polycarbonate $0.2 \mu \mathrm{m}$ porosity membranes (Bio-Rad Laboratories) were transferred to the surface of other agar media. In both cases coupled transfers were made in each direction, i.e. + inhibitor $\rightarrow-$ inhibitor and - inhibitor $\rightarrow+$ inhibitor. For example, an inhibitor-free plate, from which fruiting droplet areas on agar discs had been removed, itself received agar discs bearing droplet inocula areas from an inhibitor-rich plate. In this way the complication was avoided of utilized $\rightleftharpoons$ fresh medium transfers superimposed on the absence or presence of inhibitor.

Viable myxospores. In some experiments the presence of mature myxospores was checked by a heat-resistance test involving samples of cell material from fruiting plates being resuspended in $8 \mathrm{mM}^{-\mathrm{MgSO}_{4}} .7 \mathrm{H}_{2} \mathrm{O}$ solution and heated to $50^{\circ} \mathrm{C}$ for $20 \mathrm{~min}$. Such heat-treated material was then plated for colony formation on $1 \mathrm{CMPA}$, or for plaque formation in lawns of Micrococcus luteus on the same medium, and for growth and subsequent fruiting on 0.05 CMPA.

\section{RESULTS}

\section{Spot-tests for fruiting inhibition}

A patterned array of $30 \mu \mathrm{l}$ droplets of 1 CMP liquid culture of $M$. xanthus was placed on the surface of pre-dried 0.05 CMPA plates around a centrally-positioned $10-30 \mathrm{mg}$ sample of powdered test compound. Thus the various droplet areas lay in a diffusion gradient of the test compound. After surface moisture had dried into the agar the plates were incubated at $30^{\circ} \mathrm{C}$ and examined at daily intervals until there was no further growth or fruiting-body formation. This avoided the erroneous scoring as fruiting inhibitors those compounds which merely retarded, but did not prevent, fruiting. Some of the compounds, listed in Table 1, which allowed vegetative growth but prevented fruiting were tested further and minimal inhibitory concentrations for fruiting determined. These were caffeine, $1 \mathrm{mg} \mathrm{m}^{-1}$; chloro IPC, $250 \mu \mathrm{g}$ $\mathrm{ml}^{-1}$; DL-norleucine, $500 \mu \mathrm{g} \mathrm{ml}^{-1}$; 6-methylaminopurine, $380 \mu \mathrm{g} \mathrm{ml}^{-1}$; L-methionine, $200 \mu \mathrm{g} \mathrm{ml}^{-1}$; 6-methylpurine, $100 \mu \mathrm{g} \mathrm{ml}^{-1}$; and L-isoleucine, $2 \mathrm{mg} \mathrm{ml}^{-1}$, and were used in challenge time-transfer experiments (see below). In addition, preliminary tests with 20 different 
Table 1. Compounds tested for inhibition of $M$. xanthus fruiting-body formation

Inhibition was tested on water/magnesium/phosphate/agar plus $0.05 \%(w / v)$ enzymically hydrolysed casein. Only confirmed results from two or more reproducible repeat tests are shown.

Compounds allowing growth but inhibiting fruiting

Purines, etc.
Caffeine $(1,3,7$-trimethylxanthine $)$
Theophylline (1,3-dimethylxanthine)
Aminophylline [(Theophylline $)_{2}$.ethylenediamine]
6-Methylaminopurine $\left(N^{6}\right.$-methyladenine)
Adenine
2-Aminopurine
2,6-Diaminopurine
6-Benzylaminopurine
6-Methylpurine
6-Mercaptopurine
Amino acids
Isoleucine
Threonine
Lysine
Methionine
Tryptophan
Phenylalanine
Norleucine
Other agents
Hadacidin* ( $N$-formyl- $N$-hydroxy aminoacetic acid)
Chloro IPC [Isopropyl- $N$-(3-chlorophenyl)carbamate]
Compounds not inhibiting fruiting

\author{
Adenosine \\ Theobromine (3,7-dimethylxanthine) \\ Xanthine \\ Gramicidin
}

- Shimkets \& Dworkin (1981).

sugars, based on the possibility of a lectin role in aggregation (Cumsky \& Zusman, 1979), failed to show any inhibition of fruiting.

\section{Growth inhibitors}

Compounds which appeared to interfere with fruiting by mere inhibition of growth were tested further. Spot-tests were performed on the surface of 1 CMPA plates, using a patterned array of inocula droplets around a sample of the test compound as in the fruiting-inhibition tests on a poorer medium, above. The minimal concentrations of some agents for growth inhibition on 1 CMPA medium were determined. They were: D-cycloserine, $250 \mu \mathrm{g} \mathrm{ml}^{-1}$; indole, $375 \mu \mathrm{g} \mathrm{ml}^{-1}$; novobiocin, $0.4 \mu \mathrm{g} \mathrm{ml}^{-1}$; nalidixic acid, $200 \mu \mathrm{g} \mathrm{ml}^{-1}$; polymyxin B, $500 \mu \mathrm{g} \mathrm{ml}^{-1}$; sodium azide, $100 \mu \mathrm{g} \mathrm{ml}^{-1}$; L-canavanine, $150 \mu \mathrm{g} \mathrm{ml}^{-1}$; aminophenylbutanoic acid, $2 \mathrm{mg} \mathrm{ml}^{-1}$; and azaleucine, $1.5 \mathrm{mg} \mathrm{ml}^{-1}$. Samples of spontaneous resistant mutants were obtained in the cases of D-cycloserine, polymyxin B, rifampicin, azide, novobiocin, and nalidixic acid. Most of these resistant mutants were not deficient in fruiting ability. This is in contrast to the behaviour of about $20 \%$ of the rifampicin-resistant mutants which, as found previously by Rudd \& Zusman (1979), were fruiting-defective.

\section{Challenge time-transfer experiments}

These experiments were performed with caffeine, L-methionine, 6-methylaminopurine, DLnorleucine, and 6-methylpurine at the fruiting-inhibitory concentrations shown above. The detailed results of four such experiments are shown in Table 2. While there was some interexperiment variation in the exact timing of the sequence of events in the fruiting process, consideration of the stage of the process at which transfers were made gave consistent results. These findings, and those of numerous similar experiments (results not shown) can be interpreted as showing that delayed addition of inhibitors up to the stage of late aggregation blocks subsequent fruiting-body formation. Thus myxospore formation within aggregation mounds, perhaps subsequent to controlled autolysis of a large fraction of the population and 
Table 2. Challenge time-transfer experiments with fruiting inhibitors and $M$. xanthus on 0.05 CMPA plates at $30^{\circ} \mathrm{C}$

Key: v., vegetative cells; e.a., early aggregation; a., definite aggregates formed; l.a., late, well-defined, compact aggregates; f., opaque, myxospore-containing fruiting bodies.

\begin{tabular}{|c|c|c|c|c|c|}
\hline \multirow[b]{2}{*}{ Conditions used } & \multirow{2}{*}{$\begin{array}{l}\text { Time of } \\
\text { transfer } \\
\text { (h) }\end{array}$} & \multicolumn{2}{|c|}{- Inhibitor $\vec{i}+$ inhibitor } & \multicolumn{2}{|c|}{+ Inhibitor $\rightarrow-$ inhibitor } \\
\hline & & $\begin{array}{l}\text { Stage at } \\
\text { transfer* }\end{array}$ & $\begin{array}{c}\text { Final } \\
\text { morphology }\end{array}$ & $\begin{array}{l}\text { Stage at } \\
\text { transfer* }\end{array}$ & $\begin{array}{c}\text { Final } \\
\text { morphology }\end{array}$ \\
\hline $\begin{array}{l}\text { 6-Methylpurine, } 100 \mu \mathrm{g} \mathrm{ml}^{-1} \\
\text { Agar disc transfers, final } \\
\text { scoring at } 6 \mathrm{~d}\end{array}$ & $\begin{array}{c}16-21 \cdot 5 \\
23 \\
27 \cdot 2 \\
40 \\
41 \cdot 8 \\
45 \cdot 3 \\
48 \\
51 \cdot 5-65 \cdot 5 \\
69 \\
72\end{array}$ & $\begin{array}{l}\text { v. } \\
\text { v. } \\
\text { e.a. } \\
\text { a. } \\
\text { a. } \\
\text { a. } \\
\text { a. } \\
\text { l.a. } \\
\text { f. } \\
\text { f. }\end{array}$ & $\begin{array}{l}\text { v. } \\
\text { v. }+ \text { a. } \\
\text { v. + a. } \\
\text { v. + l.a. } \\
\text { a. } \\
\text { l.a. } \\
\text { l.a. } \\
\text { f. } \\
\text { f. } \\
\text { f. }\end{array}$ & $\begin{array}{l}\text { v. } \\
\text { v. } \\
\text { v. } \\
\text { v. } \\
\text { v. } \\
\text { v. } \\
\text { v. } \\
\text { v. } \\
\text { v. } \\
\text { v. }\end{array}$ & $\begin{array}{l}\text { f. } \\
\text { f. } \\
\text { f. } \\
\text { f. } \\
\text { a. } \\
\text { v. } \\
\text { a. } \\
\text { a. } \\
\text { a. } \\
\text { v. }\end{array}$ \\
\hline $\begin{array}{l}\text { DL-Norleucine, } 500 \mu \mathrm{g} \mathrm{ml}^{-1} \\
\text { Uni-Pore membrane transfers, } \\
\text { final scoring at } 7 \mathrm{~d}\end{array}$ & $\begin{array}{r}24-28 \cdot 8 \\
30 \cdot 5-32 \cdot 7 \\
48 \cdot 5 \\
50 \cdot 3 \\
53 \cdot 8-59 \cdot 8 \\
71-100 \cdot 5\end{array}$ & $\begin{array}{l}\text { v. } \\
\text { e.a. } \\
\text { a. } \\
\text { a. } \\
\text { l.a. } \\
\text { f. }\end{array}$ & $\begin{array}{l}\text { v. } \\
\text { e.a. } \\
\text { f. } \\
\text { f. } \\
\text { f. } \\
\text { f. }\end{array}$ & $\begin{array}{l}\text { v. } \\
\text { v. } \\
\text { e.a. } \\
\text { e.a. } \\
\text { e.a. } \\
\text { e.a. }\end{array}$ & $\begin{array}{l}\text { f. } \\
\text { f. } \\
\text { l.a. } \\
\text { a. } \\
\text { a. } \\
\text { a. }\end{array}$ \\
\hline $\begin{array}{l}\text { Caffeine, } 1 \mathrm{mg} \mathrm{ml}^{-1} \\
\text { Uni-Pore membrane transfers, } \\
\text { final scoring at } 7 \mathrm{~d}\end{array}$ & $\begin{array}{r}24-28 \cdot 8 \\
30 \cdot 5-32 \cdot 7 \\
48 \cdot 5 \\
50 \cdot 3 \\
53 \cdot 8-56 \cdot 5 \\
59 \cdot 8 \\
71 \\
74 \\
78 \cdot 3-100 \cdot 5\end{array}$ & $\begin{array}{l}\text { v. } \\
\text { e.a. } \\
\text { a. } \\
\text { a. } \\
\text { l.a. } \\
\text { l.a. } \\
\text { l.a. } \\
\text { l.a. } \\
\text { f. }\end{array}$ & $\begin{array}{l}\text { v. } \\
\text { v. } \\
\text { e.a. } \\
\text { e.a. } \\
\text { e.a. } \\
\text { e.a. } \\
\text { a. } \\
\text { l.a. } \\
\text { f. }\end{array}$ & $\begin{array}{l}\text { v. } \\
\text { e.a. } \\
\text { e.a. } \\
\text { e.a. } \\
\text { e.a. } \\
\text { e.a. } \\
\text { e.a. } \\
\text { e.a. } \\
\text { e.a. }\end{array}$ & $\begin{array}{l}\text { f. } \\
\text { f. } \\
\text { f. } \\
\text { l.a. } \\
\text { l.a. }+ \text { f. } \\
\text { l.a. } \\
\text { a. } \\
\text { a. } \\
\text { a. }\end{array}$ \\
\hline $\begin{array}{l}\mathrm{L}-\text { Methionine, } 200 \mu \mathrm{g} \mathrm{ml}^{-1} \\
\text { Uni-Pore membrane transfers, } \\
\text { final scoring at } 5 \mathrm{~d}\end{array}$ & $\begin{array}{r}19-25 \cdot 5 \\
26 \cdot 5-29 \cdot 5 \\
43 \\
45 \\
47 \cdot 8-51 \cdot 6 \\
67 \cdot 5 \\
69 \cdot 3 \\
72 \cdot 8-78 \cdot 6 \\
90\end{array}$ & $\begin{array}{l}\text { v. } \\
\text { e.a. } \\
\text { a. } \\
\text { a. } \\
\text { a. } \\
\text { l.a. } \\
\text { l.a. } \\
\text { f. } \\
\text { f. }\end{array}$ & $\begin{array}{l}\text { e.a. } \\
\text { e.a. } \\
\text { l.a. } \\
\text { l.a. } \\
\text { f. } \\
\text { f. } \\
\text { f. } \\
\text { f. } \\
\text { f. }\end{array}$ & $\begin{array}{l}\text { v. } \\
\text { v. } \\
\text { v. } \\
\text { e.a. } \\
\text { e.a. } \\
\text { e.a. } \\
\text { e.a. } \\
\text { e.a. } \\
\text { e.a. }\end{array}$ & $\begin{array}{l}\text { f. } \\
\text { f. } \\
\text { f. } \\
\text { f. } \\
\text { f. } \\
\text { l.a. } \\
\text { a. } \\
\text { e.a. } \\
\text { v. }\end{array}$ \\
\hline
\end{tabular}

adenosine accumulation (Wireman \& Dworkin, 1975, 1977; Shimkets \& Dworkin, 1981), is blocked by the inhibitors. Conversely, vegetative cells may be kept for moderate periods in the presence of the inhibitors, at the stage of early aggregation, yet retain the ability to fruit subsequently when the inhibitor is removed. However, if kept for extended periods in the presence of the inhibitor, beyond the time when well-defined aggregates would normally be formed, they no longer fruit on delayed removal of the inhibitor even though there is ample time for them to do so. Heat-resistance tests suggest that in some circumstances, where cells are prevented by inhibitors from forming full-sized aggregates at the normal time, they form, rather, free-lying myxospores. However, 6-methylpurine, norleucine or methionine (Inouye et al., 1979) seem to block such free-lying, heat-resistant, myxospore formation.

\section{DISCUSSION}

Caution is necessary in the interpretation of our results. Firstly, as noted by Rosenberg et al. (1973), for the specific case of methionine contamination of commercially available 
'methionine-free' leucine, effects apparently due to high concentrations of one compound may in fact be due to lower concentrations of a contaminating substance. Secondly, we have checked cases of apparent growth-inhibition on fruiting medium by further tests on 1 CMPA plates. However, 1 CMPA contains 20 times as much Casitone as the fruiting medium. Thus Casitone components might prevent growth inhibition by a test compound on 1 CMPA but fail to do so on the poorer fruiting medium (Cleary \& Foster, 1978). Thirdly, the transfer techniques used in the challenge-time experiments (agar plug or membrane filter transfers) did not involve washing the cells free of any adsorbed or intracellular nutrients or inhibitors. To have attempted to do so would have disrupted the cell aggregates and the normal fruiting process. Thus we have relied on rapid dilution out of any carried-over nutrients or inhibitors, by diffusion into the underlying agar layer. It is possible that the exact timing of some inhibitory events might have appeared different if an effective method of very rapid removal of compounds from cells, under fruiting conditions on a surface, could have been devised.

Compounds causing inhibition of fruiting body formation, without affecting vegetative growth, could act in a number of different ways. They might, for example, inhibit cell movement so that the cells could not move to aggregation foci. Alternatively there might be an interference with the production, perception, response to, or destruction of, normal motility-aggregation signals. Fruiting inhibition could also result from blockage or derangement of normal slime production, programmed autolysis (Shimkets \& Dworkin, 1981), or prevention of myxospore formation. Thus while some fruiting inhibitors might prevent aggregation, yet allow the formation of free-lying myxospores (as do some mutations - Hagen et al., 1978), others might allow aggregation yet block the formation of myxospores. In virtually all of the published accounts these distinctions between different possible modes of action of fruiting inhibitors have not been made.

Our research has been supported by S.R.C. grants and by funds from U.E.A. We are grateful to Drs Kate McCann, Martin Jones, Howard Foster and Peter Miller, and to Wendy Cleary, Diane Hawkins, and Richard Brown for information and encouragement.

\section{REFERENCES}

CAMPos, J. M. \& Zusman, D. R. (1975). Regulation of development in Myxococcus xanthus: effect of $3^{\prime}: 5^{\prime}-$ cyclic AMP, ADP, and nutrition. Proceedings of the National Academy of Sciences of the United States of America 72, 518-522.

Cleary, W. G. \& Foster, H. A. (1978). Inhibition of vegetative growth and fruiting body formation in Myxococcus xanthus. FEMS Microbiology Letters 4, 265-269.

Cumsky, M. \& Zusman, D. R. (1979). Myxobacterial haemagglutinin: a development-specific lectin of Myxococcus xanthus. Proceedings of the National Academy of Sciences of the United States of America 76, 5505-5509.

DwORKIN, M. (1963). Nutritional regulation of morphogenesis in Myxococcus xanthus. Journal of Bacteriology 86, 67-72.

Hagen, D. C., Bretscher, A. P. \& Kaiser, D. (1978). Synergism between morphogenetic mutants of Myxococcus xanthus. Developmental Biology 64, 284296.

Hemphill, H. E. \& ZaHLeR, S. A. (1968). Nutritional induction and suppression of fruiting in Myxococcus xanthus. Journal of Bacteriology 95, 1018-1023.

Ho, J. \& MCCURDY, H. D. (1980). Sequential changes in the cyclic nucleotide levels and cyclic nucleotide phosphodiesterase activities during development of Myxococcus xanthus. Current Microbiology 3, 197202.
INOUYe, M., INOUYE, S. \& ZUSMAN, D. R. (1979). Gene expression during development of Myxococcus xanthus: pattern of protein synthesis. Developmental Biology 68, 579-591.

LEADBETTER, E. R. (1963). Control of growth and morphogenesis in some Myxococcus species. Nature, London 200, 1127-1128.

MANOIL, C. \& KAISER, D. (1980a). Accumulation of guanosine tetraphosphate and guanosine pentaphosphate in Myxococcus xanthus during starvation and myxospore formation. Journal of Bacteriology 141, 297-304.

MANOIL, C. \& KaISER, D. (1980 b). Guanosine pentaphosphate and guanosine tetraphosphate accumulation and induction of Myxococcus xanthus fruiting body development. Journal of Bacteriology 141, 305315.

MaNoIL, C. \& KaISER, D. (1980c). Purine-containing compounds, including cyclic adenosine $3^{\prime}, 5^{\prime}$-monophosphate, induce fruiting of Myxococcus xanthus by nutritional imbalance. Journal of Bacteriology 141, 374-377.

MorRison, C. E. \& Zusman, D. R. (1979). Myxococcus xanthus mutants with temperature-sensitive, stagespecific defects: evidence for independent pathways in development. Journal of Bacteriology 140, 10361042. 
Rosenberg, E., Filler, D., ZAFriti, D. \& Kindler, S. H. (1973). Aspartokinase activity and the developmental cycle of Myxococcus xanthus. Journal of Bacteriology 115, 29-34.

Rudd, K. \& Zusman, D. R. (1979). Rifampinresistant mutants of Myxococcus xanthus defective in development. Journal of Bacteriology 137 295-300.

ShimkeTs, L. J. \& Dworkin, M. (1981). Excreted adenosine is a cell density signal for the initiation of fruiting body formation in Myxococcus xanthus. Developmental Biology 84, 51-60.

Wireman, J. W. \& DWORKIN, M. (1975). Morphogenesis and developmental interactions in myxobacteria. Science 189, 516-522.

WIREMAN, J. W. \& DWORKIN, M. (1977). Developmentally induced autolysis during fruiting body formation by Myxococcus xanthus. Journal of Bacteriology 129, 796-802. 